\title{
SYNTHESIS AND CHARACTERIZATION OF CHITOSAN- SILICA HYBRID ADSORBENT FROM THE EXTRACTION OF TIMOR-EAST NUSA TENGGARA ISLAND SILICA AND ITS APPLICATION TO ADSORPTION OF COPPER(II) ION
}

\author{
Johnson N. Naat ${ }^{1, *}$, Titus Lapailaka ${ }^{2}$, Akhmad Sabarudin ${ }^{3, *}$ \\ and Rachmat Triandi Tjahjanto ${ }^{3}$ \\ ${ }^{1}$ Chemistry Education Department, Faculty of Education and Teachers Training, University of \\ Nusa Cendana, Kupang-85001, East Nusa Tenggara, Indonesia \\ ${ }^{2}$ Chemistry Department, Faculty of Science and Technology, University of Nusa Cendana, \\ Kupang-85001, East Nusa Tenggara, Indonesia \\ ${ }^{3}$ Department of Chemistry, Faculty of Science, Brawijaya of University, \\ Malang-65145, East Java, Indonesia \\ *E-mail: johnson_naat@staf.undana.ac.id, sabarjpn@ub.ac.id
}

\begin{abstract}
Chitosan-silica hybrid adsorbent has been successfully synthesized by extracting the silica of Timor Island-East Nusa Tenggara (NTT) in order to study its application to $\mathrm{Cu}^{2+}$ adsorption in water samples. This work consists of several steps which include silica extraction from Takari sand of East Nusa Tenggara, preparation of chitosan-silica hybrid, FTIR and SEM characterization, and adsorption of $\mathrm{Cu}^{2+}$. The successful extraction of silica was indicated by the existence of-OH, siloxane ( $\mathrm{Si}-\mathrm{O}-\mathrm{Si}), \mathrm{Si}-\mathrm{O}$ in silanol $(\mathrm{Si}-\mathrm{OH})$ peaks at $3433.29 \mathrm{~cm}^{-1}, 468.70 \mathrm{~cm}^{-1}$, and 958.62 $\mathrm{cm}^{-1}$, respectively. The formation of chitosan-silica hybrid adsorbent was denoted by a peak shift of-OH in silica to3404.36 $\mathrm{cm}^{-1}$, N-H stretching vibration at $1544.98 \mathrm{~cm}^{-1}$ due to an interaction between $\mathrm{O}-\mathrm{H}$ in silica with $\mathrm{N}-\mathrm{H}$ in chitosan, and amine (primary-NH) bending vibration at $1639.49 \mathrm{~cm}^{-1}$. The surface morphology of silica changed when it was modified with chitosan from homogeneous granule to a cluster (larger particle sizes). Optimum adsorption conditions toward $\mathrm{Cu}^{2+}$ were achieved at $\mathrm{pH} 8$ and contact time of 50 min, resulting in excellence adsorption efficiency of $99.3 \%$. Adsorption of $\mathrm{Cu}^{2+}$ fitted Langmuir isotherm with the adsorption capacity of 27 $\mathrm{mg} / \mathrm{g}$.
\end{abstract}

Keywords: Natural sand, chitosan-silica hybrid, Isotherm, $\mathrm{Cu}^{2+}$ adsorption

(C) RASĀYAN. All rights reserved

\section{INTRODUCTION}

Heavy metals are often released into the environment from many industries such as industry of petrochemical, leather, paint, metallurgical, battery and car radiator manufacturing, metal plating, and textile industries as well as from agricultural sources and mining operations ${ }^{1,2}$. These heavy metals have widely known for their toxic effect to human and the environment ${ }^{3}$. Some examples of heavy metals that pollute water are $\mathrm{Cr}(\mathrm{VI}), \mathrm{Cd}(\mathrm{II}), \mathrm{Pb}(\mathrm{II}), \mathrm{Zn}(\mathrm{II}), \mathrm{Hg}(\mathrm{II}), \mathrm{Fe}(\mathrm{II})$, and $\mathrm{Cu}(\mathrm{II})^{4}$. Specifically for copper, it is a moderate metal that has good conductor properties, and it was also combined with other metals for used in many fields ${ }^{5}$. The widespread copper used has caused water environment problems. The presence of copper in industrial waste is commonly in the form of bivalent $\mathrm{Cu}^{2+}$ as its hydrolytic product. The toxic effect of $\mathrm{Cu}^{2+}$ occurred when its amount is excessing the tolerable limit to living organisms or certain component of environment ${ }^{4,6}$. If humans consume water that contains an excessive amount of $\mathrm{Cu}^{2+}$, it will cause illnesses such as vomits, diarrhea, burning to feel in the esophagus and gastric, colic, hypotension, liver necrosis, and coma ${ }^{6}$.

Rasayan J. Chem., 11(4), 1467-1476(2018)

http://dx.doi.org/10.31788/RJC.2018.1144055

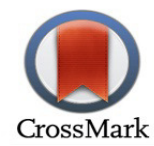


According to WHO, the maximum amount of $\mathrm{Cu}^{2+}$ allowed in territorial water is $0.2 \mathrm{mg} / \mathrm{L}^{7}$. Thus, there will be acts needed to reduce $\mathrm{Cu}^{2+}$ in water.

Some researchers have developed various methods such as chemical precipitation, coagulation, adsorption, ion exchange and membrane filtration for the removal of heavy metals from water and wastewaters ${ }^{8}$. The limitations associated with these methods are high operational cost, sludge production and they differ in their effectiveness, especially when metals are present in solution at very low concentrations. Of all the treatment methods mentioned above, adsorption had been reported as an efficient method for the removal of heavy metals from aqueous solution because of their effectiveness even at low concentration ${ }^{9,10}$.

Adsorption is an adhesion process of the certain matter by the surface of a solid. This adhesion is caused by the electrostatic interaction of atoms or molecules on the surface of a solid without absorbing it into the pores of the adsorbent it self ${ }^{11}$. This adsorption process is a promising affordable method because of its simplicity and efficiency ${ }^{12}$. The method is conducted based on its interaction between metal ions and functional groups on the surface of the adsorbent by forming a complex compound. The surface is rich in functional groups such as $-\mathrm{OH},-\mathrm{NH},-\mathrm{SH}$ and- $\mathrm{COOH}^{11}$. Silica gel in the silanol group can be modified. Silica is an ideal candidate of solid because it is stable in the acidic environment, a nonswelling agent, it has high mass change transfer characteristic, good porosity and surface area, and is stable in high temperature $^{12}$. Silica gel is able to act as the base of an adsorbent because it will adsorb heavy metal ions or hazardous pollutants because of its silanol $(\mathrm{Si}-\mathrm{OH})$ and siloxane $(\mathrm{Si}-\mathrm{O}-\mathrm{Si})$ groups ${ }^{13}$. Silica gel alone is not effective yet as an adsorbent because oxygen (silanol and siloxane) has the low capability as an electron donating group ${ }^{14}$. Hence, modification by adding an active agent like chitosan is needed.

Chitosan is a derivative from deacetylated chitin ${ }^{15,16}$. It is able to adsorb ions in wastewater because it has free amine groups $\left(-\mathrm{NH}_{2}\right)$ and hydroxyl $(-\mathrm{OH})$ groups that work as the chelation site (coordinating bond site) with the ions to form achelate ${ }^{17,18}$. Chitosan also has the disadvantage of not resistant to acid, so that the structure is fragile, so can modify with materials such as silica ${ }^{19,20}$.

This work utilizes the potential and abundance of Takari sand in East Nusa Tenggara, especially in Timor Island, as the source of silica. Takari sand has a good quality due to its high character of softness and cleanliness. Based on previous research using fluorescence $\mathrm{x}$-ray, the composition of silica $\left(\mathrm{SiO}_{2}\right)$ in Takari sand is $32.9 \%$ whereas, after the extraction, its composition increased to $97.8 \%$. This paper will be the pioneer of information about the synthesis of silica-based adsorbent extracted from Takari sand of Timor Island-East Nusa Tenggara, modified with chitosan, to eliminate $\mathrm{Cu}^{2+}$ in a sample of water. In our work, the chitosan-silica hybrid adsorbent material was synthesized using a sol-gel method with minor modification to get the microspheres structures to enhancing the adsorption performance of $\mathrm{Cu}(\mathrm{II})$ from the water sample. Sol-gel technique was chosen to use in this research because this method commonly has been used to form chitosan-silica hybrid materials with potential properties for the adsorption process ${ }^{21,22}$. This adsorbent silica-chitosan hybrid was then characterized using FTIR and SEM to study the functional group of silica and modified silica-chitosan and also their morphology. Some parameters affecting the performance adsorption of $\mathrm{Cu}^{2+}$ including optimum $\mathrm{pH}$, contact time, concentration, adsorption capacity, and isotherm adsorption were studied in detail.

\section{Reagent and Materials}

\section{EXPERIMENTAL}

Chitosan (75-85\% deacetylation degree), nitric acid ( $\mathrm{HNO}_{3}$, puriss. p.a., $\left.\geq 65 \%\right)$, acetic acid $\left(\mathrm{CH}_{3} \mathrm{COOH}\right.$, $100 \%(\mathrm{v} / \mathrm{v})$ ), Hydrochloric acid $(\mathrm{HCl} 37 \%)$ and natrium tripolifosfat $\left(\mathrm{Na}_{5} \mathrm{P}_{3} \mathrm{O}_{10}, 85 \% \mathrm{w} / \mathrm{w}\right)$ were purchased from Merck (Singapore). Copper(II) sulfate pentahydrate $\left(\mathrm{CuSO}_{4} .5 \mathrm{H}_{2} \mathrm{O}\right.$, ACS reagent, $\geq 98.0 \%$ ), Sodium hydroxide $(\mathrm{NaOH})$ puriss. p.a.) was purchased from Sigma Aldrich (Singapore). Aqua demineralization was produced in our lab. The natural sand was collected from Takari Timor Island-NTT

\section{General Procedure}

\section{Silica Extraction}

Takari sand was washed and cleaned with aquadest and processed using a wide stirrer at $272.72 \mathrm{rpm}$ for 5 min. This process was repeated 3 times. The sand was dried in an oven at $105^{\circ} \mathrm{C}$ for $2 \mathrm{~h}$. Then, it was 
soften using a disk mill at 200 mesh. 50 gram of sand was soaked in $200 \mathrm{~mL}$ of $2 \mathrm{M} \mathrm{HCl}$ for $12 \mathrm{~h}$. The sand was washed with aquadest until reached neutral $\mathrm{pH}$. The sand was filtered and dried in an oven at $105{ }^{\circ} \mathrm{C}$ for $2 \mathrm{~h}$. The result was processed to form a homogeneous sand powder. $4 \mathrm{~g}$ of powder was diluted in $60 \mathrm{~mL}$ of $7 \mathrm{M} \mathrm{NaOH}$ and refluxed at $90{ }^{\circ} \mathrm{C}$ using a magnetic stirrer for $4 \mathrm{~h}$ until sodium silicate was formed. The mixture was mixed in $60 \mathrm{~mL}$ of aquadest for $24 \mathrm{~h}$. Then filtered using no. 42 Whatman filter paper and titrated with $2 \mathrm{M} \mathrm{HCl}$ until reached $\mathrm{pH} 7$ to form a white precipitate. The precipitation was dried in room temperature and cleaned using aquadest 5 times. Finally, it was filtered and dried in an oven at $105^{\circ} \mathrm{C}$ for 5 hours ${ }^{23,24}$.

\section{Synthesis of Chitosan-Silica Hybrid Adsorbent}

Chitosan solution was made by diluting $2 \mathrm{~g}$ of chitosan in $100 \mathrm{~mL}$ of $3 \%$ acetic acid and constantly stirred using a magnetic stirrer for $1 \mathrm{~h}$ to form a homogeneous solution ${ }^{24} .1 \mathrm{~g}$ silica that had been prepared was mixed with chitosan solution and stirred to form a homogenous mixture for $12 \mathrm{~h}$. The mixture was then neutralized with $50 \mathrm{~mL}$ of $1 \mathrm{M} \mathrm{NaOH}$ and diluted until a precipitation was formed. It was decantated and washed with aquadest 3 times and then filtered. The precipitation was reacted with $30 \mathrm{~mL}$ of $3 \%$ acetic acid and mixed with $50 \mathrm{~mL}$ of $1 \%$ sodium tripolyphosphate $(\mathrm{b} / \mathrm{v})$ then stirred using a magnetic stirring for $1 \mathrm{~h}$. The result was filtered using a no. 1 Whatman filter paper and heated in an oven at $60{ }^{\circ} \mathrm{C}$ for $5 \mathrm{~h}$. Finally, the mixture was cooled inside a desicator ${ }^{24,25}$.

\section{Analysis and Characterization}

The functional group spectra of the chitosan-silica hybrid were characterized using Fourier-Transform Infrared Spectroscopy (FTIR) type Prestige-21 Shimadzu. Scanning Electron Microscope (SEM) merk FEI type Inspect-S50 was using to examine the surface morphology and compound of the chitosan-silica hybrid particles. $\mathrm{Cu}(\mathrm{II})$ before and after adsorption was determined using Atomic Absorption Spectroscopy (AAS) AA-7000 Shimadzu series.

\section{Optimum pH Determination}

$0.1 \mathrm{~g}$ of the chitosan-silica hybrid was interacted with $25 \mathrm{~mL}$ of $5 \mathrm{ppm} \mathrm{Cu}^{2+}$ for $50 \mathrm{~min}$ and stirred using a magnetic stirrer at $300 \mathrm{rpm}$. $\mathrm{pH}$ of the solution was made in variations of acidity $(\mathrm{pH} \mathrm{4-8})^{15}$. The solution was filtered and the filtrate produced was analyzed using AAS.

\section{Optimum Contact Time Determination}

$0.1 \mathrm{~g}$ of the chitosan-silica hybrid was interacted with $25 \mathrm{~mL}$ of $5 \mathrm{ppm} \mathrm{Cu}^{2+}$ and stirred using a magnetic stirrer at $300 \mathrm{rpm}$ and optimum $\mathrm{pH}$. Interaction time was variated at 30, 40, 50, 60, and 70 minutes ${ }^{26,27}$. The solution was filtered and the filtrate produced was analyzed using AAS.

\section{Preparation of Standard Solution of $1000 \mathrm{ppm} \mathrm{Cu}^{2+}$}

$1 \mathrm{~g}$ of $\mathrm{CuSO}_{4} .5 \mathrm{H}_{2} \mathrm{O}$ was diluted in aqua dest. Then, 3 drops of $\mathrm{HNO}_{3}$ was added. Finally, the mixture was added with aquadest in a $1000 \mathrm{~mL}$ Erlenmeyer flask until reached the limit marker ${ }^{26}$.

\section{Determination of Calibration Curve}

Calibration curve of $\mathrm{Cu}^{2+}$ was made by series of $\mathrm{Cu}^{2+}$ solution at $0.5 ; 1 ; 2 ; 3 ; 4$; and $5 \mathrm{ppm}$. Then, the series absorbance was calculated using AAS. The graph of concentration vs absorbance was made to obtain its linear regression equation.

\section{Determination of Optimum Concentration}

$0.1 \mathrm{~g}$ of the chitosan-silica hybrid interacted with $25 \mathrm{~mL}$ of $\mathrm{Cu}^{2+}$ with variations of concentration at 20, 40, 60, 80 and $100 \mathrm{mg} / \mathrm{L}$. The interaction was done at optimum time and $\mathrm{pH}$ that had been determined. Then, the mixture was stirred using a magnetic stirrer at $300 \mathrm{rpm}$. The result was filtered using a filter paper. The filtrate obtained was determined using AAS to determine the concentration of $\mathrm{Cu}^{2+}$ left. Adsorbed ions can be calculated using the equation 1 as follow ${ }^{2,28}$ :

$$
\mathrm{C}_{\mathrm{adsorbed}}=\mathrm{C}_{0}-\mathrm{C}_{\mathrm{e}}
$$


Where $\mathrm{C}_{\text {adosrbed }}$ is the difference between the concentration of ion before and after the process. Both concentrations were determined using an AAS. Then, adsorption efficiency was determined using equation-2 as $^{2}$ :

$$
\% \mathrm{Ep}=\frac{\mathrm{C}_{\text {initial }}-\mathrm{C}_{\text {remnant }}}{\mathrm{C}_{\text {initial }}} \times 100 \%
$$

\section{Determination of Adsorption Capacity}

Langmuir and Freundlich's equation was used to determine the adsorption model of adsorbent ${ }^{28}$. Langmuir adsorption isotherm was determined using equation 3 and Freundlich equation was calculated using equation-4:

$$
\frac{\mathrm{C}_{\mathrm{e}}}{\mathrm{q}_{\mathrm{e}}}=\frac{1}{\mathrm{X}_{\mathrm{m}} \mathrm{K}}+\frac{\mathrm{C}_{\mathrm{e}}}{\mathrm{X}_{\mathrm{m}}}
$$

Where Ce is the concentration of ions remnant $(\mathrm{mg} / \mathrm{L})$, qeis the concentration of adsorbed ions at equilibrium $(\mathrm{mg} / \mathrm{L}), \mathrm{Xmis}$ the maximum adsorption capacity $(\mathrm{mg} / \mathrm{g})$ and $\mathrm{K}$ is equilibrium constant. The equation forFreundlich isotherm was expressed as follow:

$$
\mathrm{q}_{\mathrm{e}}=\mathrm{K} \mathrm{C}_{\mathrm{e}}{ }^{1 / \mathrm{n}}
$$

If the equation was transformed into its logarithm form, it will be expressed by an equation as follow ${ }^{29}$ :

$$
\log \mathrm{q}_{\mathrm{e}}=\log \mathrm{K}+\frac{1}{n} \log \mathrm{C}_{\mathrm{e}}
$$

Where $\mathrm{q}_{\mathrm{e}}$ is the concentration of adsorbed ions at equilibrium $(\mathrm{mg} / \mathrm{g}), \mathrm{C}_{\mathrm{e}}$ is the concentration of ions remnant $(\mathrm{mg} / \mathrm{L}), \mathrm{K}$ is Freundlich constant and $n$ is adsorption capacity $(\mathrm{mg} / \mathrm{g})$. In Langmuir equation, $\mathrm{C}_{\mathrm{e}}$ is the concentration of ions remnant $(\mathrm{mol} / \mathrm{g}), \mathrm{q}_{\mathrm{e}}$ is the concentration of adsorbed ions at equilibrium $(\mathrm{mol} / \mathrm{g})$, $\mathrm{K}$ is equilibrium constant (adsorption affinity), $\mathrm{X}_{\mathrm{m}}$ is the amount of ions adsorbed at saturated condition (adsorption capacity). Plot 1 /qevs $1 / \mathrm{Ce}$ will obtain linear line so that the equilibrium constant $\mathrm{K}$ and adsorption capacity $\mathrm{X}_{\mathrm{m}}$ can be determined using it's using intercept and slope. In Freundlich equation, $\mathrm{q}_{\mathrm{e}}$ is the concentration of adsorbed ions at equilibrium $(\mathrm{mg} / \mathrm{g}), \mathrm{K}$ is a constant, $n$ is Freundlich adsorption capacity, and $\mathrm{C}_{\mathrm{e}}$ is the concentration of ions remnant $(\mathrm{mg} / \mathrm{L})$. Plot $\log$ qevs $\log$ Ce will obtain linear line so that the equilibrium constant $\mathrm{K}$ and adsorption capacity can be determined using it's using intercept and slope.

\section{RESULTS AND DISCUSSION \\ Characterization of Silica and Silica-Chitosan Hybrid using FTIR}

The silanol groups could react with hydroxyl groups from chitosan or form the hydrogen bond during a reaction of condensation, were resulting from hydrolysis of the precursor therewith leading to nucleation of silica on macro-molecules. The groups of amino in a molecule of chitosan was supported siloxane hydrolysis and silanol groups condensation as well as silanol groups of the silica reaction with the groups of the polymer carbonyl ${ }^{21}$. The Fig.-1 was shown the functional groups of extracted silica from Timor Island-East Nusa Tenggara and silica-chitosan hybrid.

Figure-1 informs the absorption band at $3404.36 \mathrm{~cm}^{-1}$ and $3433.29 \mathrm{~cm}^{-1}$ is the peak of the overlapping of $\mathrm{Si}-\mathrm{OH}$ stretch and amine band respectively ${ }^{21}$. The wide absorption and shifting at $3404.36 \mathrm{~cm}^{-1} \mathrm{could}_{\text {be }}$ caused by the override of $-\mathrm{NH}$ in amine of silica-chitosan or caused by the interaction of - $\mathrm{OH}$ group in silica with the $-\mathrm{NH}$ group in chitosan. The peak is related to the functional group of silica and chitosansilica hybrid, which is $1648.98 \mathrm{~cm}^{-1}$ that indicate $-\mathrm{NH}$ in chitosan. Bending vibration of $-\mathrm{OH}$ in silanol was shown by a peak at $1629.85 \mathrm{~cm}^{-1}$ that had been shifted and the intensity had also been decreased to1639.49 $\mathrm{cm}^{-1}$. The bending vibration of siloxane group ( $\mathrm{Si}-\mathrm{O}-\mathrm{Si}$ ) in silica was shown by a sharp band at $468.70 \mathrm{~cm}^{-1}$ while chitosan-silica hybrid has its vibration with low intensity. The absorption at $958.62 \mathrm{~cm}^{-}$ ${ }^{1}$ shows a stretching vibration of Si-O silanol $(\mathrm{Si}-\mathrm{OH})^{30}$. This sharp band at $1097.50 \mathrm{~cm}^{-1}$ had been shifted to $1099.43 \mathrm{~cm}^{-1}$ which were the stretching vibration of $-\mathrm{C}-\mathrm{O}-(\text { stretching vibration of } \mathrm{C}-\mathrm{O} \text { in } \mathrm{C}-\mathrm{O}-\mathrm{NH})^{31}$. The spectrum of chitosan-silica hybrid adsorbent shows the new functional group at $1544.98 \mathrm{~cm}^{-1}$ and this 
RASĀYAN J. Chem.

Vol. 11 | No. 4 |1467 - 1476| October - December | 2018

peak is also known as the peak of N-H bond from primary Amine salt ${ }^{30}$. A peek at $1411.89 \mathrm{~cm}^{-1}$ shows aliphatic $\mathrm{P}=\mathrm{O}$ formed by cross-bonding formation with sodium tripolyphosphate.

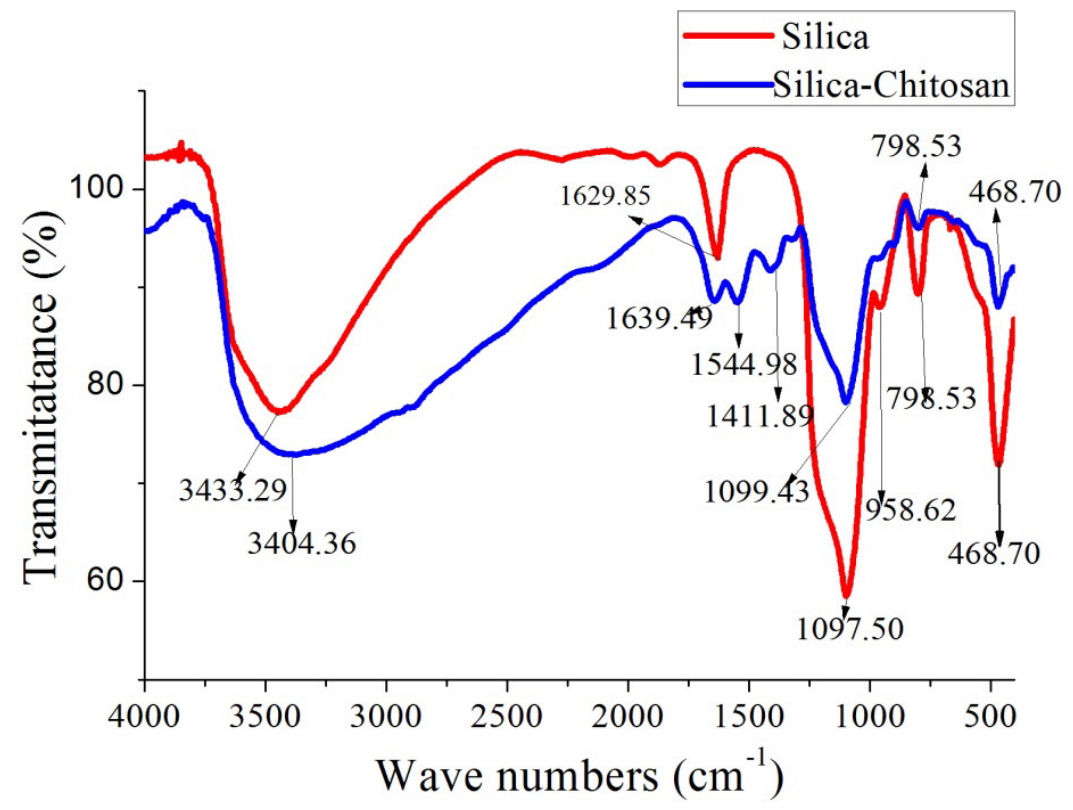

Fig.-1: FTIR Spectrum of Silica and Chitosan-Silica Hybrid

Characterization of Silica and Silica-Chitosan Hybrid Adsorbent using SEM

The image of morphology SEM of extracted silica and the silica-chitosan hybrid was shown by Fig.-2.
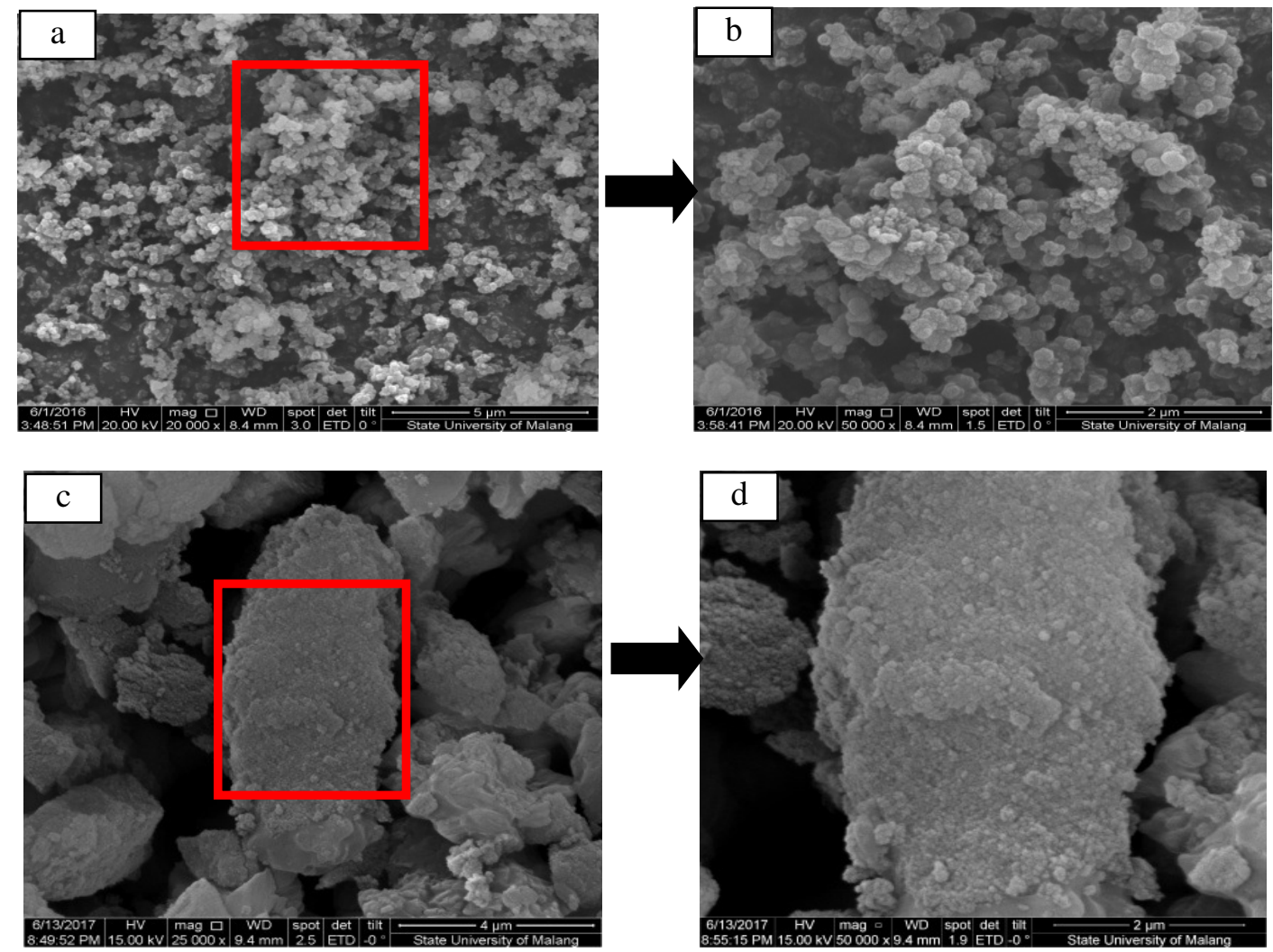

Fig-2: (a) and (b) Morphology of the Surface of Extracted Silica with a Magnification of 20.000x and 50.000x, (c) and (d) Morphology of the Surface of a Chitosan-Silica Hybrid with a Magnification of 25.000x and 50.000x 
RASĀYAN J. Chem.

Vol. 11 | No. 4 |1467 - 1476| October - December | 2018

Figure-2(a) and (b) show that the particles of silica looked like homogenous granules and the grain boundaries were seen crystal clear. Silica particles also formed a rough cluster. Those particles agglomerated to form a bigger microparticle. Meanwhile, the morphology of chitosan-silica hybrid with the magnification of $25.000 \mathrm{x}$ and $50.000 \mathrm{x}$ show agglomerated granules were forming bigger clusters that indicated the sample interacted to each other. Particles shown have a relatively equal size that distributed equally so that the grain boundary was seen clearly.

\section{The Bonding Model of Silica-Chitosan Hybrid Adsorbent with $\mathrm{Cu}^{2+}$}

The silica-chitosan hybrid adsorbent is a multifunctional polymer that contains amine $\left(-\mathrm{NH}_{2}\right)$ groups and silanol $(-\mathrm{OH})$ groups. The amount of $-\mathrm{NH}_{2}$ on the surface of the adsorbent was reduced when silica was increasing and then outspread the $\mathrm{Cu}^{2+}$ adsorption ${ }^{22}$. These groups allow the adsorbent to have high reactivity and to act as an electron donating group so that it is able to interact with heavy metal cations. In the complex formation of $\mathrm{Cu}^{2+}$ and $\mathrm{N}$ from chitosan-silica hybrid adsorbent, we can explain this reaction with crystal field theory (CFT). The interaction between metal and ligand is purely an electrostatic interaction. Transition metal ion as the central atom is considered as the positive ion, surrounded by ligands with a negative charge or neutral molecules with lone electron pairs.

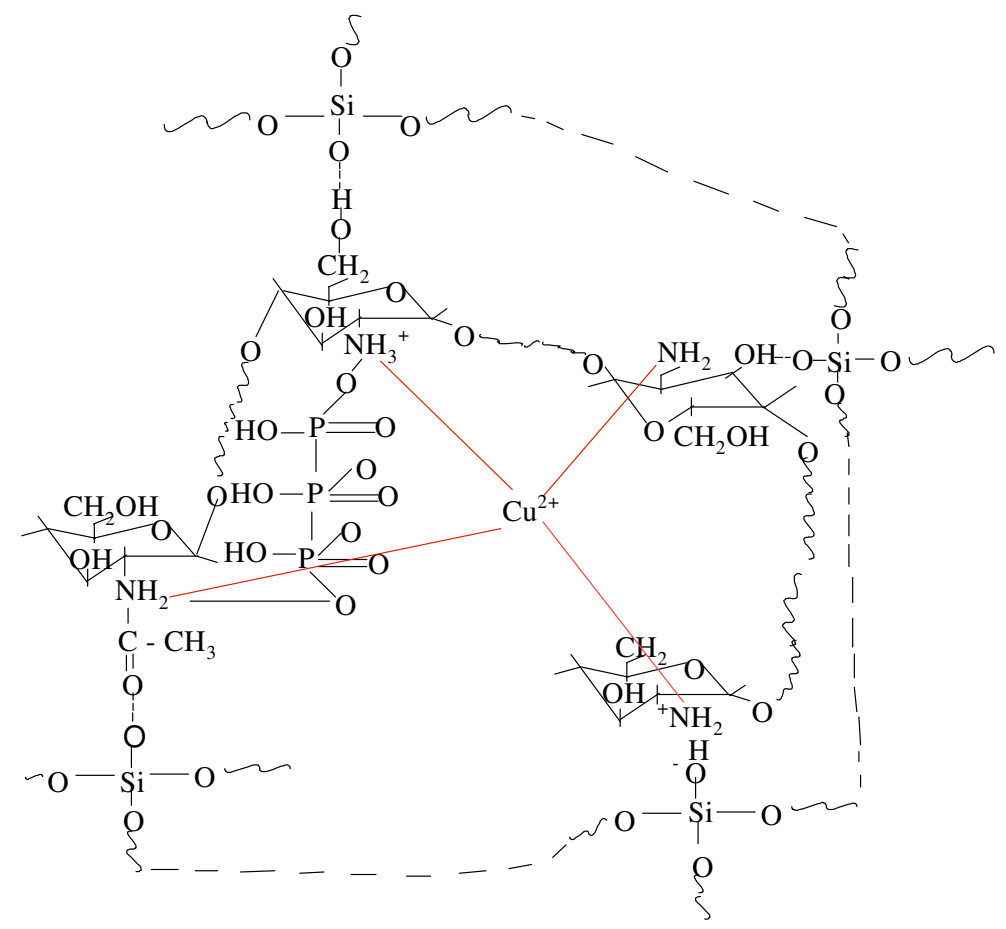

Scheme-1: Prediction of Complex Formation Between Chitosan-Silica Hybrid Adsorbent and $\mathrm{Cu}^{2+}$

\section{Optimation of $\mathbf{p H}$ and Time Contact of $\mathrm{Cu}^{2+}$ Adsorption}

Optimation of $\mathrm{pH}$ is shown by Fig.-3(a). This optimation was conducted to know the optimum condition of acidity of the adsorbent to adsorb $\mathrm{Cu}^{2+}$. According to Fig.-3(a), there was an increase of $\mathrm{Cu}^{2+}$ adsorbed at $\mathrm{pH} 5$ to 8 . This was caused by the abundance of $\mathrm{H}^{+}$ions in the solution. At that acidity, $\mathrm{H}^{+}$ ions bond with $\mathrm{OH}^{-}$ions that caused $-\mathrm{NH}_{2}$ in the adsorbent have a bigger probability to bond with $\mathrm{Cu}^{2+}$. Meanwhile, at $\mathrm{pH} 9, \mathrm{H}^{+}$ions were ceased to exist so that $\mathrm{OH}^{-}$ions would also react with $\mathrm{Cu}^{2+}$ because of its higher reactivity. The presence of $\mathrm{H}^{+}$ions in the solution causes a competitive reaction between $\mathrm{H}^{+}$and $\mathrm{Cu}^{2+}$ ions with lone electron pairs of cross-linked chitin-sodium tripolyphosphate, which were the lone electrons of $-\mathrm{O}-$ of amide groups.

Figure-3a shows that at $\mathrm{pH} 9$, the adsorption of $\mathrm{Cu}^{2+}$ was decreased. This might be caused by the decrease of $\mathrm{H}^{+}$ions. This change in adsorbent and adsorbate cause weaker interaction between them so that the adsorbed $\mathrm{Cu}^{2+}$ is also decreased. In conclusion, the optimum acidity of the reaction is $\mathrm{pH} 8$ with the 
RASĀYAN J. Chem.

Vol. 11 | No. 4 |1467 - 1476| October - December | 2018

highest adsorption capacities $\left(0.633 \mathrm{mg} / \mathrm{g}\right.$. Fig.-3b shows optimation curve of $\mathrm{Cu}^{2+}$ adsorption. This result was correlated with the research of Budnyak et al. $(2014)^{32}$.
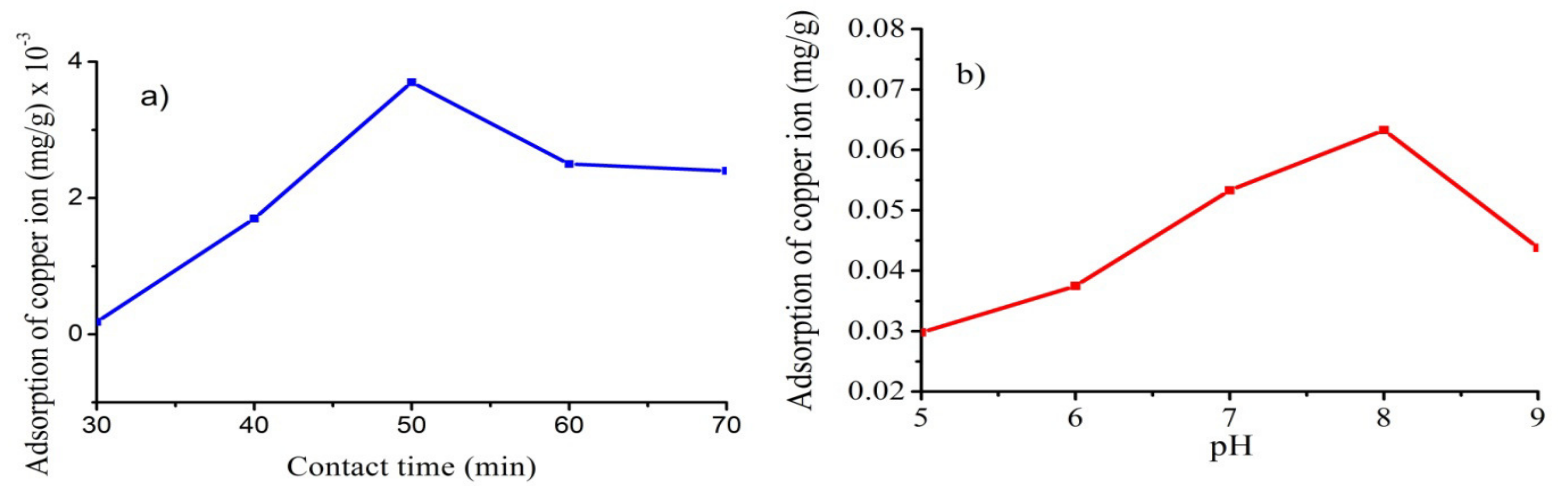

Fig.-3: (a) Optimation Curve of $\mathrm{pH}$ of $\mathrm{Cu}^{2+}$ Adsorption, (b). Optimation Curve of Contact time of $\mathrm{Cu}^{2+}$ Adsorption

This analysis, using an AAS, shows the increase of adsorbed $\mathrm{Cu}^{2+}$ with the contact time of 30 to 50 minutes. This could be caused by the equilibrium factor where cross-linked chitosan-sodium tripolyphosphate adsorption to $\mathrm{Cu}^{2+}$ had not been achieved. At equilibrium, it is seen that there is no longer increase but what is seen is the decrease of adsorption. After passing the optimum contact time, adsorption will be stopped because the active site on the chitosan-silica hybrid has been saturated of $\mathrm{Cu}^{2+}$. This caused a release of $\mathrm{Cu}^{2+}$ ions that have been bonded with the adsorbent. Another probability was caused by the shrink of adsorbent pores due to time. Optimum contact time is 50 min with the adsorption capacities is $3.7 \times 10^{-3} \mathrm{mg} / \mathrm{g}$. Base on the literature data, chitosan-silica hybrid has a high adsorption capacity of the $\mathrm{Cu}^{2+}$ at the range of contact time between 15 to 50 minutes depending on optimization parameters separately ${ }^{31}$.

\section{Optimation of Initial Concentration}

Optimation of concentration for this adsorption process is to study at what amount $\mathrm{Cu}^{2+}$ will be adsorbed optimally and stable. Data of optimation is shown by Table-1and Fig.-4.

Table-1: Adsorbed $\mathrm{Cu}^{2+}$ in Chitosan-Silica Hybrid at Varieties of Concentration

\begin{tabular}{c|c|c}
\hline $\begin{array}{c}\text { Initial concentration } \\
\text { of } \mathrm{Cu}^{2+}(\mathrm{mg} / \mathrm{L})\end{array}$ & $\begin{array}{c}\text { Adsorption of } \mathrm{Cu}^{2+} \\
(\mathrm{mg} / \mathrm{g})\end{array}$ & $\begin{array}{c}\text { Adsorption } \\
\text { Efficiency }(\%)\end{array}$ \\
\hline 20 & 4.8038 & 96.0 \\
\hline 40 & 9.6765 & 96.7 \\
\hline 60 & 14.0424 & 99.3 \\
\hline 80 & 19.4353 & 97.1 \\
\hline 100 & 23.9616 & 95.8 \\
\hline
\end{tabular}

Table-2 and Fig.-4 show the efficiency of adsorption is increased from an initial concentration of 20-60 $\mathrm{mg} / \mathrm{L}$ and decreased the initial concentration of $80-100 \mathrm{mg} / \mathrm{L}$ so that the optimum concentration of $\mathrm{Cu}^{2+}$ happens at an initial concentration of $60 \mathrm{mg} / \mathrm{L}$ with the adsorbed ions of $14 \mathrm{mg} / \mathrm{g}$ and efficiency of $99.3 \%$. When the initial concentration is below $60 \mathrm{mg} / \mathrm{L}$, the amount $\mathrm{Cu}^{2+}$ in solution is less than the amount of binding site of chitosan silica-hybrid adsorbent so that there is an increase in adsorption. On the contrary, when the initial concentration is below $60 \mathrm{mg} / \mathrm{L}$, the amount $\mathrm{Cu}^{2+}$ in solution is less than the amount of binding site of chitosan-silica hybrid adsorbent so that the process is stopped at an optimum concentration. This increase of adsorbate shows the adsorption capacity of adsorbent is decreased. This is caused by the collision between adsorbate and adsorbent is increased that decreases the adsorption capacity.

\section{Adsorption Isotherms Modeling}

Modeling isotherm adsorption was determined using Langmuir adsorption equation (Equ.-3) and Freundlich equation (Equation-4). To determine the isotherm for both equation, $1 / \mathrm{C}_{\mathrm{e}}, 1 / \mathrm{q}_{\mathrm{e}}, \log \mathrm{C}_{\mathrm{e}}$, and $\log$ $\mathrm{q}_{\mathrm{e}}$ must be calculated as shown by Table- 2 . 
RASĀYAN J. Chem.

Vol. 11 | No. 4 |1467 - 1476| October - December | 2018

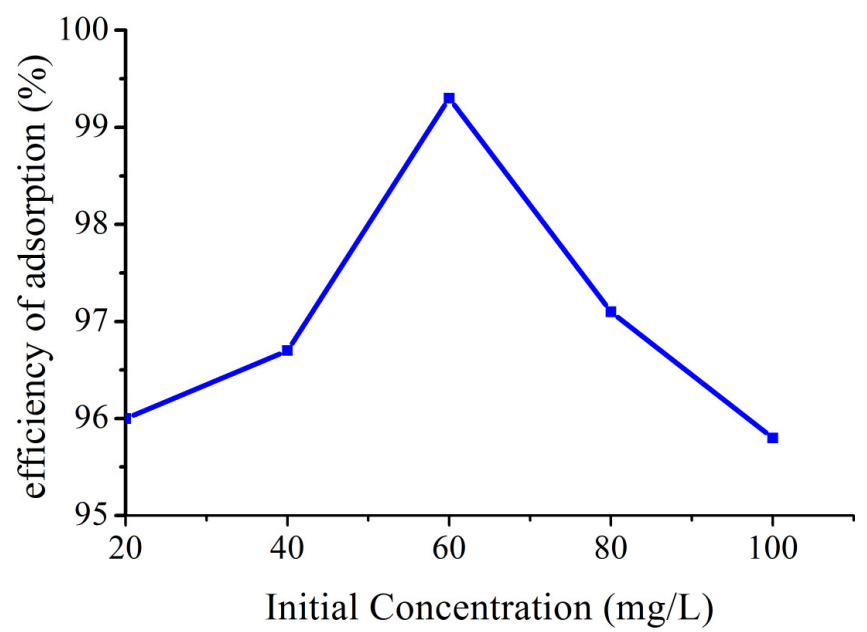

Fig.-4: Relationship Curve of Concentration Vs Efficiency of Adsorbed $\mathrm{Cu}^{2+}$

Table-2: $\mathrm{Cu}^{2+}$ Adsorption Data at Various Concentration

\begin{tabular}{c|c|c|c|c}
\hline Initial concentration $(\mathrm{mg} / \mathrm{L})$ & $1 / \mathrm{C}_{\mathrm{e}}$ & $1 / \mathrm{q}_{\mathrm{e}}$ & $\log \mathrm{C}_{\mathrm{e}}$ & $\log \mathrm{q}_{\mathrm{e}}$ \\
\hline 20 & 1.2742 & 0.0520 & -0.1052 & 1.2836 \\
\hline 40 & 0.7728 & 0.0258 & 0.1119 & 1.5877 \\
\hline 60 & 0.2610 & 0.0178 & 0.5832 & 1.7495 \\
\hline 80 & 0.4427 & 0.0128 & 0.3538 & 1.8906 \\
\hline 100 & 0.2407 & 0,0104 & 0.6184 & 1.9815 \\
\hline
\end{tabular}

The result from Table- 2 then plotted into $1 / \mathrm{C}_{\mathrm{e}}$, versus $1 / \mathrm{q}_{\mathrm{e}}$ graph to determine the Langmuir equation (Fig.-5) and also plotted into $\log \mathrm{C}_{\mathrm{e}}$ versus $\log \mathrm{q}_{\mathrm{e}}$ (Fig.-6) to determine its Freundlich equation. Langmuir and Freundlich adsorption test was proven by their good linearity of the graph that gives determination coefficient of $R^{2} \geq 0,9$ (close to 1$)^{33}$.

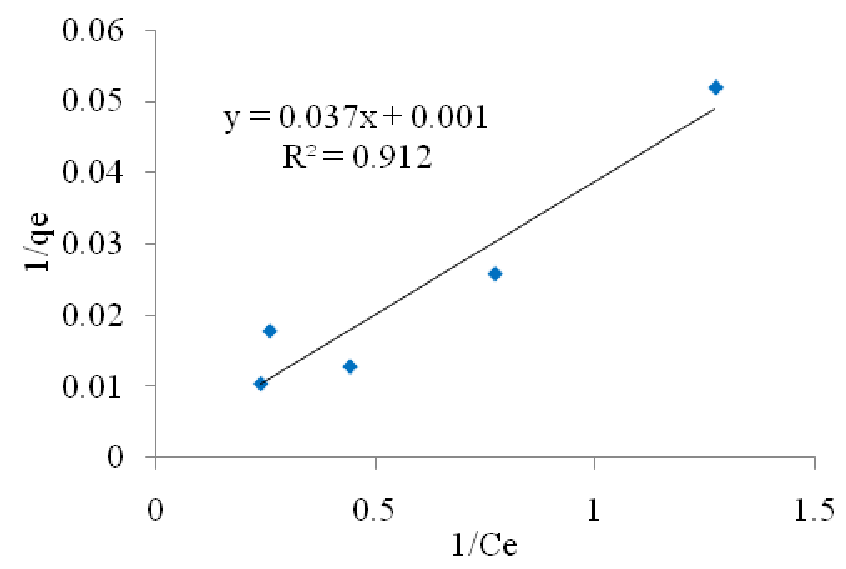

Fig.-5: Langmuir Isotherm Graph of $1 / C_{e}$ vs $1 / q_{e}$

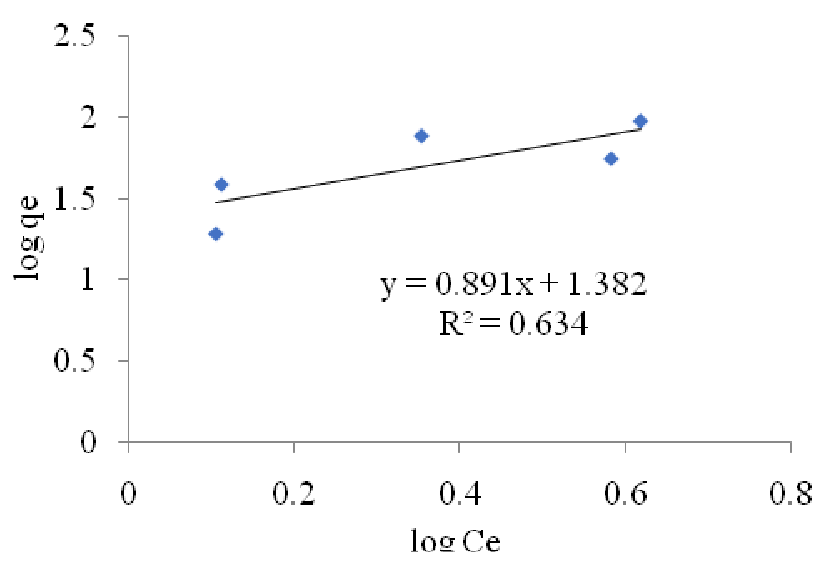

Fig.-6: Freundlich Isotherm Graph of $\log C_{e}$ vs $\log q_{e}$

Figures-5 and 6 show the R values of Langmuir was higher than Freundlich suggested that the Langmuir isotherm was more suitable than the Freundlich isotherm for this adsorbent. Regression equation obtained from $1 / C_{e}$ vs $1 /$ qeis $y=0.037 x+0.001$. From the slope and intercept, adsorption capacity $\left(X_{m}\right)$ of $\mathrm{Cu}^{2+}$ is $27.027 \mathrm{mg} / \mathrm{g}$. This result indicated that the surface of this adsorbent has active, homogenous sites and monolayer properties that are proportional to its surface area ${ }^{28}$. Each active site will only adsorb one adsorbate molecule so that the process itself is limited to the formation of monolayers. This pattern shows that $\mathrm{Cu}^{2+}$ adsorption is dominated by sites of chemical adsorption which is happened because of the 
RASĀYAN J. Chem.

Vol. 11 | No. 4 |1467 - 1476| October - December | 2018

formation of a covalent and ionic bond between $\mathrm{Cu}^{2+}$ and chitosan-silica hybrid adsorbent molecules (Scheme-1). The capacity values obtained in this study are quite highest compared to those reported in Table-3.

Table-3: Maximum Equilibrium Capacity per Mass $\left(\mathrm{X}_{\mathrm{m}}\right)$ of the Different Adsorbent for $\mathrm{Cu}^{2+}$

\begin{tabular}{c|c|c}
\hline Adsorbent & $X_{\mathrm{m}}(\mathrm{mg} / \mathrm{g})$ & References \\
\hline Silica Rice Husks Ash (RHA)-Chitosan & 9.715 & 34 \\
\hline Clays & $3-11$ & 35 \\
\hline Natural zeolit & 3.083 & 36 \\
\hline Modified SBA-15 & 11.14 & 37 \\
\hline Silica-SBA-silica-SBA-SH-2 & $8-29$ & ${ }^{38}$ \\
\hline Chitosan-SiO & 27 & This work \\
\hline
\end{tabular}

The dimensionless constant separation factor RL (Equilibrium Parameters) is an important expression of the Langmuir characteristics. The $\mathrm{R}_{\mathrm{L}}$ value can be calculated with eq- $6^{2}$ :

$$
\mathrm{R}_{\mathrm{L}}=\frac{1}{\left(1+\mathrm{K}_{\mathrm{a}} \mathrm{C}_{0}\right)}
$$

$\mathrm{C}_{0}$ is the highest initial concentration. If $0<\mathrm{R}_{\mathrm{L}}<1$, then the adsorption is favorable. If $\mathrm{R}_{\mathrm{L}}>1$, then it is not favorable. If $\mathrm{R}_{\mathrm{L}}=1$, then the adsorption is indeed linear. Finally, if $\mathrm{R}_{\mathrm{L}}=0$, then the process is irreversible. This research has the RL of $6.162 \times 10^{-4}$ which means the adsorption is favorable.

\section{CONCLUSION}

This work successfully extraction of silica was indicated by the existence of $-\mathrm{OH}$, siloxane ( $\mathrm{Si}-\mathrm{O}-\mathrm{Si}), \mathrm{Si}$ $\mathrm{O}$ in silanol $(\mathrm{Si}-\mathrm{OH})$ peaks at $3433.29 \mathrm{~cm}^{-1}, 468.70 \mathrm{~cm}^{-1}$, and $958.62 \mathrm{~cm}^{-1}$, respectively. The formation of chitosan-silica hybrid adsorbent was denoted by a peak shift of $-\mathrm{OH}$ in silica to $3404.36 \mathrm{~cm}^{-1}, \mathrm{~N}-\mathrm{H}$ stretching vibration at $1544.98 \mathrm{~cm}^{-1}$ due to an interaction between $\mathrm{O}-\mathrm{H}$ in silica with $\mathrm{N}-\mathrm{H}$ in chitosan, and amine (primary-NH) bending vibration at $1639.49 \mathrm{~cm}^{-1}$. The surface morphology of silica changed when it was modified with chitosan from homogeneous granule to a cluster (larger particle sizes). Optimum adsorption conditions toward $\mathrm{Cu}^{2+}$ were achieved at $\mathrm{pH} 8$ and contact time of $50 \mathrm{~min}$, resulting in excellence adsorption efficiency of $99.3 \%$. Adsorption of $\mathrm{Cu}^{2+}$ fitted Langmuir isotherm with the adsorption capacity of $27 \mathrm{mg} / \mathrm{g}$.

\section{ACKNOWLEDGMENT}

The authors would like to thanks the Ministry of Research Technology and Higher Education for financial support of this work under the scheme research of PKPT 2018.

\section{REFERENCES}

1. S. Almohammadi, M. Mirzaei. Adv Environ Technol., 2, 85(2016), DOI:10.22104/aet.2016.392.

2. Y.A.B. Neolaka, E.B.S. Kalla, G. Supriyanto, Suyanto, N.N.T. Puspaningsih. Rasayan J Chem., 10(2), 606(2017), DOI: 10.7324/RJC.2017.1021710.

3. J. Sorvari, L.M. Rantala, M.J. Rantala, H. Hakkarainen, T. Eeva. Environ Pollut., 145(1), 324(2007), DOI: $10.1016 /$ j.envpol.2006.03.004.

4. K. Atkovska, K. Lisichkov, G. Ruseska, A.T. Dimitrov, A. Grozdanov. J Chem Technol Metall., 53(2), 202(2018).

5. L.N. Tu, L.V. Tan, N.X. Chien. Rasayan J. Chem., 11(2), 850(2018), DOI: 10.31788/RJC.2018.1122088 2018;11(2):850-856.

6. M.H. Salmani, M.H. Ehrampoush, S. Sheikhalishahi, M. Dehvari. J Heal Res., 1(1), 11(2012)

7. WHO. Copper in Drinking-water. America (NY)., 3, 23(2011), DOI: 10.1016/j.kjms.2011.05.002.

8. A.O. Aderonke, B.A. Abimbola, E. Ifeanyi, S.A Omotayo, S.A Oluwagbemiga, W.M. Oladotun. African J Pure Appl Chem., 8(10), 147(2014), DOI:10.5897/AJPAC2014.0591

9. O.S. Amuda, T.I. Edewor, T.J. Afolabi, Y.T. Hung. Int J Environ Waste Manag., 12(2), 213(2013), DOI: $10.1504 /$ IJEWM.2013.055595

10. S. Liang, X. Guo, N. Feng, Q. Tian. J Hazard Mater. 170(1), 425(2009), DOI: 10.1016/j.jhazmat.2009.04.078 
RASĀYAN $J$. Chem.

Vol. 11 | No. 4 |1467 - 1476| October - December | 2018

11. S. A. Gevorgyan, S.S. Hayrapetyan. Proceding of the Yerefan., 51(1), 17(2017)

12. S. Radi, S. Tighadouini, M.E.1. Massaoudi, T.B. Hadda, M. Zaghrioui, M. Bacquet, J.P. Dacquin, I. Warad. J Mater Environ Sci., 5(4), 1280(2014)

13. A. Goswami, A.K. Singh. Anal Bioanal Chem., 374(3), 554(2002), DOI: 10.1007/s00216-002-15243

14. A. Purwanto, Yusmaniar, F. Ferdiani, R. Damayanti. AIP Conf Proc., 1823, 020032(2017), DOI: 10.1063/1.4978105

15. M. Ahmad, S. Ahmed, B.L. Swami, S. Ikram. Int J Pharmacogn., 2(6), 280(2015), DOI:10.13040/IJPSR.0975-8232.IJP.2(6).280-89

16. L. Gaurav, Yon-SukKim, H. Jin-Woo, K. Se-Kwon, J. You-Jin, J. Jae-Young, A. Chang-Bum, M. Sang-Ho, J. Byong-Tae, P. Pyo-Jam. Biomed Res Int., 13, 6549(2014), DOI:10.1155/2014/654913

17. W. Cao, C.J. Easley, J.P. Ferrance, J.P. Landers. Anal Chem.. 78 (20), 228(2006), DOI: 10.1021/ac0603911

18. K. Molvinger, F. Quignard, D. Brunel, M. Boissière, J. M. Devoisselle. Chem Mater., 16(17), 3367(2004), DOI: $10.1021 / \mathrm{cm} 0353299$

19. J. Du, A. Chen, X. Peng, W. Abudurman, W. Shimei, Z. Ronglan, J. Chi. J Polym Res., 21(9), (2014), DOI: 10.1007/s10965-014-0541-120

20. H. Zhou, L. Yang, G. Huajie, C. Haijun, Z. Liangzheng, Z. Aisheng, M. Li, Yuqing, Int J Nanomedicine., 7, 4649(2012), DOI:10.2147/IJN.S29690

21. M.R. Gandhi, S. Meenakshi. Int J Biol Macromol., 50(3), 650(2012) DOI:10.1016/j.ijbiomac.2012.01.01222.

22. H. Zhao, J. Xu, W. Lan, T. Wang, G. Luo. Chem Eng J., 229, 82(2013), DOI:10.1016/j.cej.2013.05.093

23. U. Kalapathy, A. Proctor, J. Shultz. Bioresour Technol., 85, 85(2002), DOI:10.1016/S09608524(02)00116-5

24. P. Saraswathi, M. Makeswari. Rasayan J Chem., 10(3), 759(2017), DOI:10.7324/RJC.2017.1031752

25. F.M. Widhi. Indo J Chem., 14(2), 131(2014)

26. M. Kenji, D. Xiaoyu, S. Sekiguchi and K. F. Naoki, J Funct Biomater Artic., 8, 51(2017), DOI: $10.3390 / \mathrm{jfb} 8040051$

27. E. Salehi, J. Abdi, M.H. Aliei. J Saudi Chem Soc., 20(2), 213(2016), DOI: 10.1016/j.jscs.2014.02.007

28. Y.A.B. Neolaka, G. Supriyanto, H.S. Kusuma. J Environ Chem Eng., 6(2), 3436(2018), DOI:10.1016/j.jece.2018.04.053

29. Y.A.B. Neolaka, E.B.S. Kalla, G.A. Malelak, N.K. Rukman, G. Supriyanto, N.N.T. Puspaningsi. Rasayan J Chem., 11(2), 494(2018), DOI:10.7324/RJC.2018.1121994

30. Y.L. Liu, Y.H. Su, J.Y. Lai. Polymer (Guildf)., 45(20), 6831(2004), DOI:10.1016/j.polymer.2004.08.006

31. M.G. Rajiv, S. Meenakshi. Int J Biol Macromol., 50(3), 650(2012), DOI:10.1016/j.ijbiomac.2012.01.012

32. T. Budnyak, V. Tertykh, E. Yanovska. Issn Mater Sci., 20(2), 1392(2014), DOI:10.5755/j01.ms.20.2.4975

33. N. Chiron, R. Guilet, E. Deydier. Water Res., 37(13), 30793086(2003), DOI:10.1016/S00431354(03)00156-8

34. H. Widwiastuti, A. Mulyasuryani, A. Sabarudin . J Pure App Chem Res., 2(1), 42(2013)

35. S. Babel, T.A. Kurniawan. J Hazard Mater., B97, 219 (2003)

36. J. Peric, M. Trgo, M.N. Vukojević. Water Res., 38(7), 1893(2004), DOI:10.1016/j.watres.2003.12.035

37. L. Giraldo, J.C. Moreno-Piraján. Mater Res., 16(4), 745(2013), DOI:10.1590/S151614392013005000051

38. Liao Q, Zeng L, Li L, Guo F, Wu L, Le S. Desalin Water Treat., 56(8), 2154(2015), DOI: 10.1080/19443994.2014.958762

[RJC-4055/2018] 